Plateau. Fig. 7 shows the phytolith-based reconstructions of temperature and precipitation in Baoji over the last $150 \mathrm{ka}$ and the $95 \%$ confidence interval.

Houyuan lu, Naigin Wu, Tungsheng Lu, Jiamo Han, XIaoguang Qin

Institute of Geology, Chinese Academy of Sciences, Beijing 100029, China

\section{Xianguun Sun}

Institute of Botany, Chinese Academy of Sciences, Beijing 100093, China

\section{YongJI Wang}

First Institute of Oceanography, State Oceanic Administration, Qingdao 266003, China

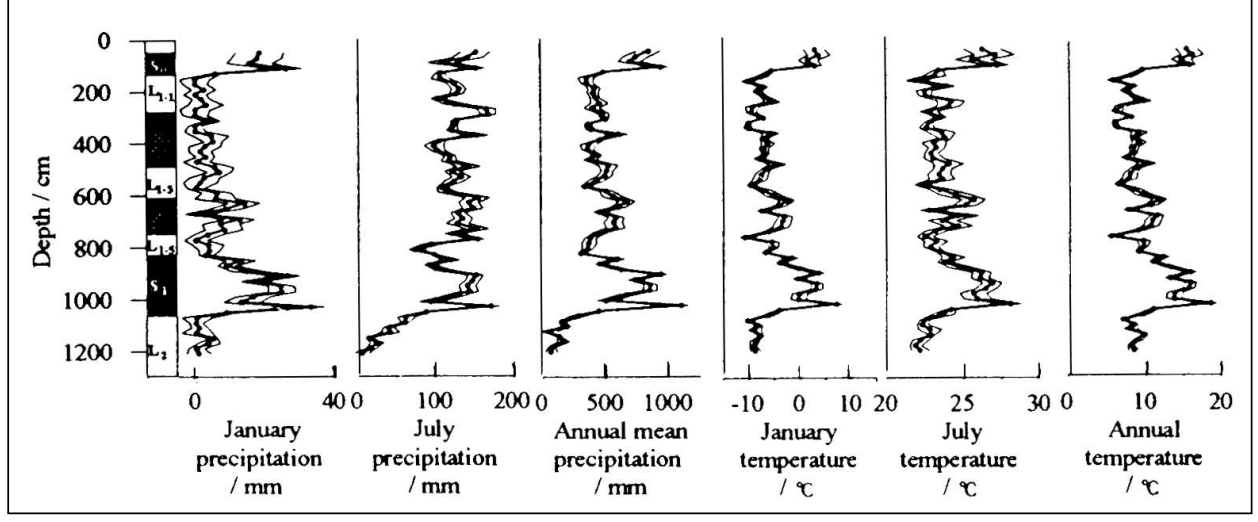

Fig. 7: Estimated temperature and precipitation variations in Baoji during the last 150 ka based on phytolith-climate transfer functions. Thick lines represent estimated regression values, fine lines are $95 \%$ confidence intervals.

\title{
Comparison of East Asian Monsoon Proxies from the Central China Loess Plateau and Lake Biwa
}

The pattern of climate in eastern Asia is dominated by the summer and winter monsoons (Gao, 1962). The loess-paleosol sequence on the Loess Plateau of central China constitutes an excellent proxy record of variations in East Asian monsoon climate over the past 2.5 Ma (An et al., 1990; 1991; Ding et al., 1995). Magnetic susceptibility (MS) of the loess and paleosols has been used as a proxy indicator for the summer monsoon intensity, i.e., high magnetic susceptibility values reflect increased summer monsoon intensity (An et al., 1991); while the median diameter of quartz (QMD) isolated from the loess and paleosols can be regarded as a proxy index of the strength of winter monsoon winds, i.e., the greater the quartz median diameter, the stronger the winter monsoon winds (Xiao et al., 1995). Studies on grain-size distribution, oxygen isotope composition and micromorphological features of monomineralic quartz isolated from sediments of Lake Biwa, central Japan suggested that quartz particles finer than $10 \mu \mathrm{m}$ were derived, through the transport of the winter monsoon, from arid/semiarid regions of the Asian continent, and thereby can be regarded as eolian quartz (Xiao et al., 1997a). By contrast, quartz grains coarser than $20 \mu \mathrm{m}$ in the Lake Biwa sediments were considered to be derived, through soil erosion, from the surrounding terrain of the lake (Xiao et al., 1997b). Eolian quartz flux (EQF) to Lake Biwa provides direct information on variations in the East Asian winter monsoon strength, i.e., the higher the eolian quartz flux, the stronger the winter monsoon winds (Xiao et al., 1997a); whereas the fluvial quartz flux (FQF) reflects significant changes in paleoprecipitation over the lake area, and thus can be associated with the intensity of the summer monsoon, i.e., high fluvial quartz flux values imply increases in summer monsoon intensity (Xiao et al., 1997b).

As shown in figure 8, the EQF and FQF records of Lake Biwa sediments can be well compared with the QMD and MS records of the Chinese loess and paleosols. The intervals of high EQF values correspond to the periods of great $Q M D$ values, whereas the intervals of high FQF values correlate to the periods of high MS values. The EQF and the QMD as winter monsoon proxies indicate that the winter monsoon strengthened during periods marked by high EQF and QMD values, and it was relatively weaker when EQF and QMD values were lower. As as summer monsoon proxies, the FQF and the MS reveal significant variations in the intensity of the summer monsoon, i.e., the higher the FQF and MS values, the stronger the summer monsoon circulation. Variations in winter monsoon strength indicated by the EQF and QMD proxies bear a general inverse relation to those in summer

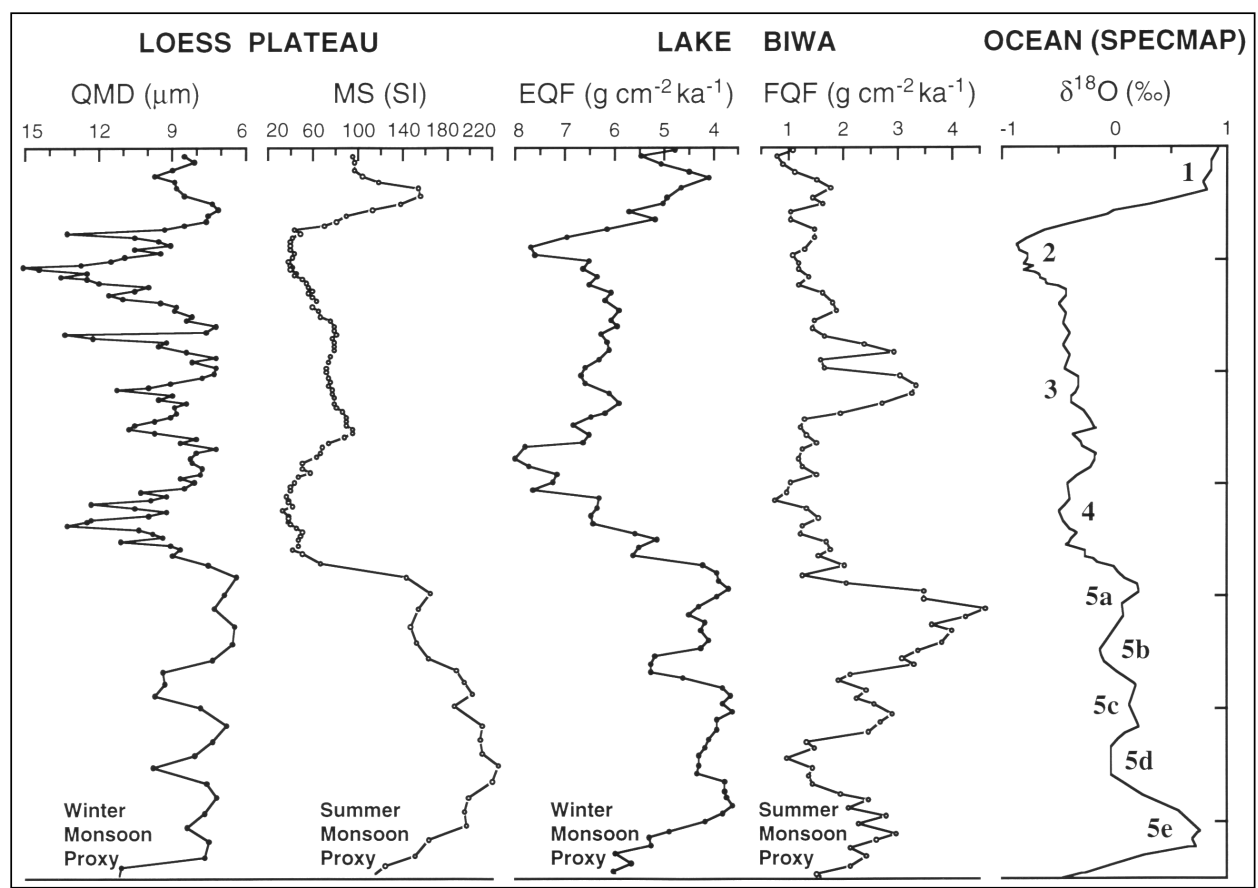

Fig. 8: Time series of the last ca. 130,000 years comparing the quartz median diameter (QMD) and magnetic susceptibility (MS) of the loess-paleosol sequence at Luochuan in the central part of the Loess Plateau and the eolian quartz flux (EQF) and fluvial quartz flux (FQF) of Lake Biwa sediments the SPECMAP $\delta^{18} \mathrm{O}$ record (from Quaternary Science Reviews, in press). monsoon intensity inferred from the $\mathrm{FQF}$ and MS proxies. paleomonsoon climate can be correlated with the SPECMAP marine $\delta^{18} \mathrm{O}$ stages 1 through 6 (Martinson et al., 1987) (Fig. 8). The main intervals of low EQF and QMD values and high FQF and MS values apparently coincide with SPECMAP $\delta^{18} \mathrm{O}$ substages $5 \mathrm{e}, 5 \mathrm{c}$, and $5 \mathrm{a}$, stage 3 , and the early part of stage 1 , while the main low FQF and MS values occurred during $\delta^{18} \mathrm{O}$ stages 4 and 2.

\section{J.L. XIAO}

Institute of Geology, Chinese Academy of Sciences, P.O. Box 9825, Beiijing 100029, China j|xiao@public3.bta.net.cn
These four proxy records of East Asian intervals of great $\mathrm{EQF}$ and QMD values and 